\title{
Surveillance, Diagnosis, Treatment, and Outcome of Liver Cancer in Japan
}

\author{
Masatoshi Kudo \\ Department of Gastroenterology and Hepatology, Kinki University School of Medicine, Osaka, Japan
}

\author{
Key Words \\ Diagnosis · Hepatocellular carcinoma · Prognosis · Surveillance/screening · \\ Treatment algorithm
}

\begin{abstract}
Background: Hepatocellular carcinoma (HCC) is the fifth most common type of cancer and the third leading cause of cancer-related death worldwide. HCC is most common in Asia, but its prevalence is rapidly increasing in Western countries; consequently, HCC is a global medical issue that urgently needs to be addressed. Japan is the only developed country that has experienced both hepatitis B-related and hepatitis C-related HCC and has a long history of innovation when it comes to new diagnostic and therapeutic modalities, such as computed tomography angiography, anatomical resection, ablation, and transarterial chemoembolization. Among these innovations, a nationwide surveillance program was well established by the 1980s, and such a long-term national program does not exist anywhere else in the world. Summary: More than $60 \%$ of the initially detected HCCs in Japan are Barcelona Clinic Liver Cancer stage 0 or $\mathrm{A}$, which can undergo curative therapies such as resection, ablation, or transplantation. The recent 5 -year survival rate of HCC patients in Japan was $43 \%$ and the median survival time was 50 months. In addition, both incidence and mortality rates are drastically declining as a result of the successful surveillance program, careful diagnostic flow, and extensive repeated treatments. Key Message: Japan's successful model in the surveillance, diagnosis, and treatment of HCC should be adopted as widely as possible to improve the survival of HCC patients worldwide.




\section{Epidemiology}

Hepatocellular carcinoma (HCC) is the fifth most common type of cancer and the third leading cause of cancer-related death worldwide [1]. Twenty to thirty years ago, liver cancer was most prevalent in Asia and Africa, but it is now rapidly becoming more prevalent in Western countries as a result of the spread of hepatitis $C$ infection and increased rates of liver cancer associated with alcohol use and non-alcoholic steatohepatitis (NASH). Liver cancer is, therefore, increasingly becoming a global problem. In Japan, nationwide followup surveys by the Liver Cancer Study Group of Japan show that the total number of deaths from liver cancer began to increase sharply in 1975, but have been declining since peaking in 2004 (fig. 1). Furthermore, data from GLOBOCAN show that the rate at which the incidence is decreasing in Japan is faster than the rate at which it was increasing sharply after 1975 [1] (fig. 2). Another reason for the declining incidence rate may be the great success of vaccination and gamma-globulin injection programs started in 1986 to prevent transmission of hepatitis B from mothers to their children. In addition, screenings of donated blood and efforts to educate the general public about hepatitis $\mathrm{C}$ have also been successful, and so the number of people newly infected by blood from tattooing or razors, as well as other sources, is also decreasing dramatically. Another factor that likely reduced the incidence of hepatitis C-related liver cancer is that a sustained virologic response (SVR, i.e., elimination of the hepatitis $\mathrm{C}$ virus) has been obtained in increasingly more patients since the advent of interferon therapy in 1992. Patients with hepatitis C and cirrhosis have also aged, so many have already died from liver cancer. For these reasons, the total number of deaths from liver cancer in Japan has noticeably decreased from its peak in 2004 (fig. 3). According to recent statistics, in 2012 a total of 30,690 people died from liver cancer in Japan.

Additionally, Japan introduced a liver cancer screening program as early as the 1980s. Although most cases were diagnosed with an alpha-fetoprotein (AFP) test or a $99^{\mathrm{m}} \mathrm{Tc}$ colloid liver scan before the 1980s, electronic ultrasound scanning devices were introduced in the early 1980s, before computed tomography (CT) and magnetic resonance imaging (MRI) were gradually introduced for the diagnosis of liver cancer. Over time, these advances contributed to the establishment of a program that made liver cancer screening possible across Japan.

In 1999, the Japan Society of Hepatology (JSH) began the Eliminate Liver Cancer Program and started publishing white papers on liver cancer. JSH has organized educational events at least once a year through appointed coordinators in each of Japan's 47 prefec-

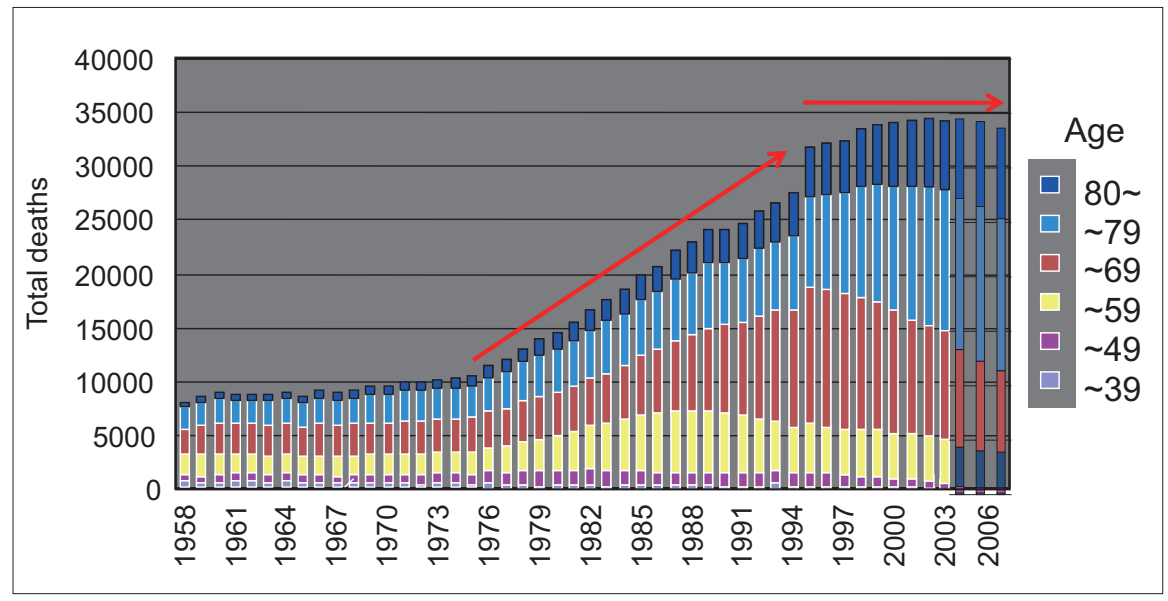

Fig. 1. Total deaths from HCC in Japan (1958-2006). 


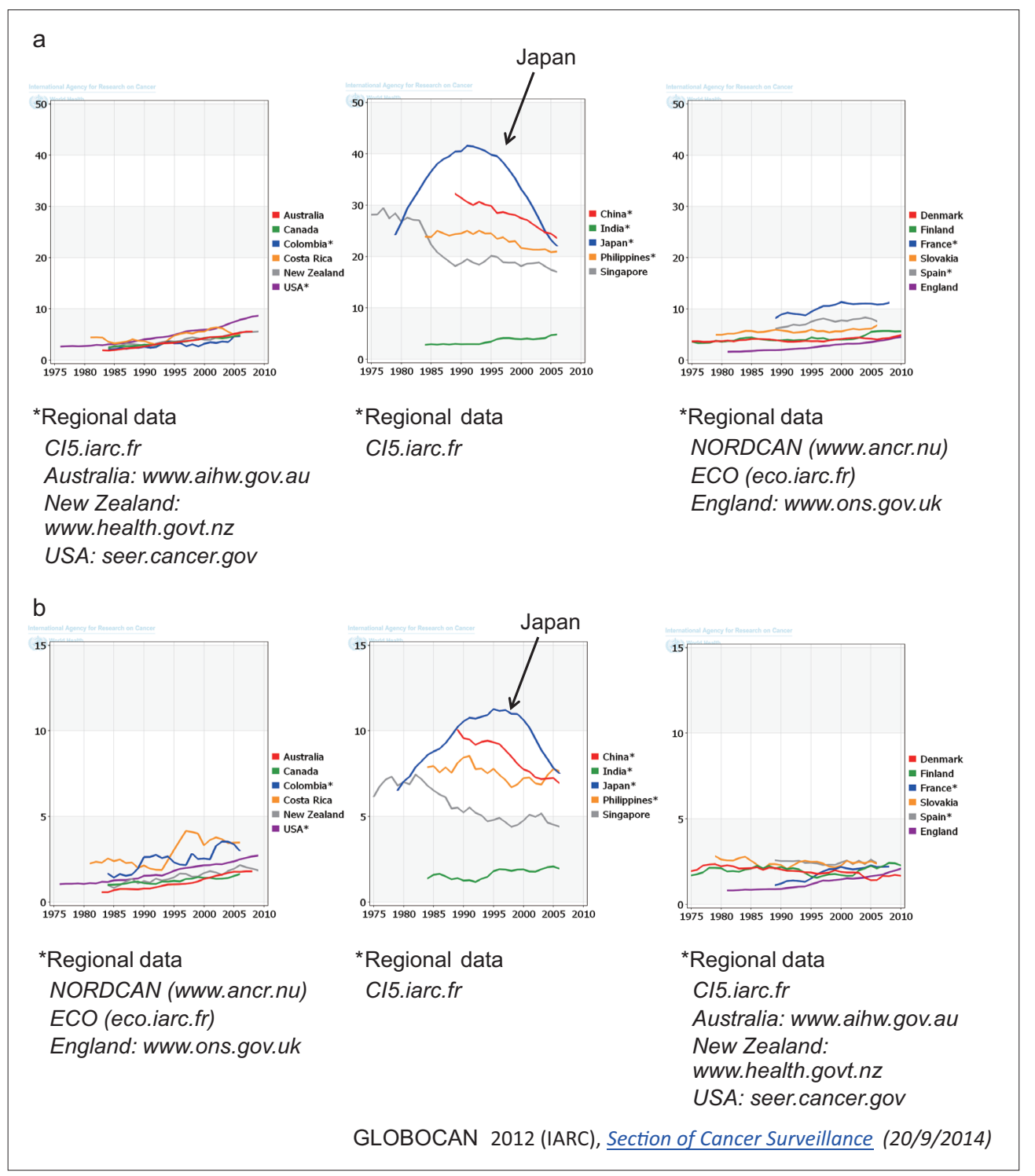

Fig. 2. a Global incidence of hepatocellular carcinoma per 100,000 population for men, clearly showing that the incidence is rapidly decreasing in Japan. b Global incidence of hepatocellular carcinoma per 100,000 population for women, clearly showing that the incidence is rapidly decreasing in Japan.

tures to educate both the general public and healthcare providers not specialized in liver cancer. Thanks to these efforts, it became possible to detect liver cancer at an early stage through regular screening of people already infected with hepatitis C or B. In addition, the Basic Act on Hepatitis Measures enacted by the Japanese Ministry of Health, Labour and Welfare (MHLW) in 2009 established a system by which public health centers and clinics could perform blood tests free of charge for the general public to check for infection with hepatitis B or C. By means of these initiatives, Japan has created the world's first nationwide HCC surveillance program, a feat that should be globally acclaimed [2]. As a result of this nationwide surveillance system, and of other advances in diagnostic and treatment methods, liver cancer is now detected at a stage where it can be treated with curative therapy, such as resec- 


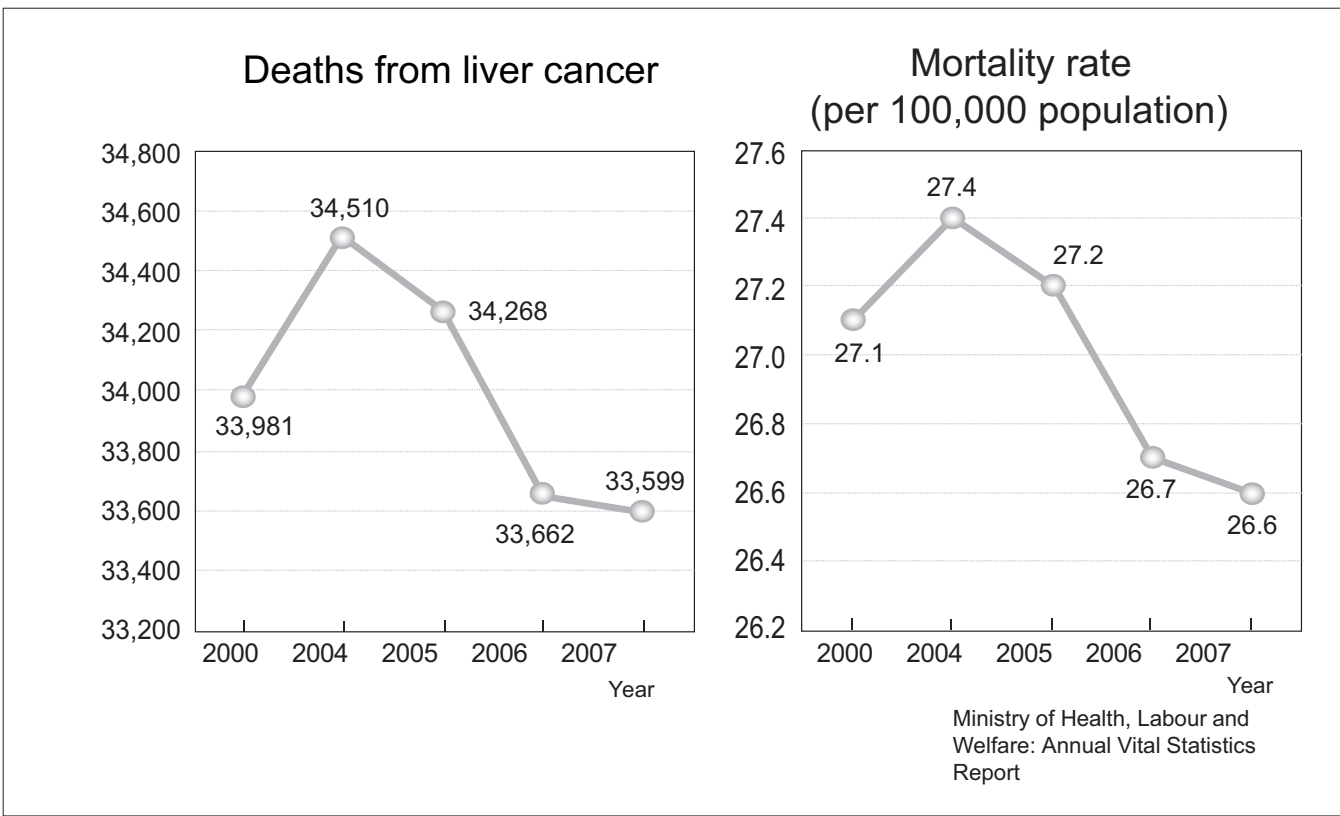

Fig. 3. Deaths from liver cancer and mortality rate in Japan.

tion [3] or ablation [4], in a larger number of patients than in other countries, and the 5-year survival rate (fig. 4) [5] and median survival time (MST) have rapidly improved (fig. 5)[5].

\section{Advances in Surveillance, Diagnostic Methods, and Treatments}

The only diagnostic method available before 1980 was contact compound ultrasound, and it was able to diagnose only cholelithiasis, because it was exceedingly difficult to detect small liver cancers with this method. At that time, liver cancer was almost always detected from the appearance of jaundice or ascites or rupturing of esophageal varices, and early detection was virtually impossible. However, in the early 1980s, image resolution improved with the transition from contact compound scanning to electronic scanning ultrasound. Around this time, physicians gradually began to conduct surveillance using ultrasound and AFP testing. In addition, hepatectomy techniques were almost fully established in 1985, making it possible to perform hepatectomy safely from that point onward. At about the same time, Yamada et al. developed transcatheter arterial chemoembolization (TACE) [6], the use of which spread widely across Japan. In the 1990s, Sugiura et al. of Chiba University established the percutaneous ethanol injection (PEI) technique, and helical CT and MRI also began to be used in the diagnosis of liver cancer. Around 1995, hepatic arterial infusion chemotherapy (HAIC) with an implanted port capable of continuous 24-h infusion was developed; this technique is unique to Japan. Several researchers demonstrated that this treatment was extremely effective (response rate: 30-40\%), and reliably improved the prognosis of patients in whom a partial or complete response was obtained [7]. As a result, HAIC began to be adopted as a de facto standard of care across Japan.

In 1992, interferon therapy for hepatitis $C$ was introduced. The initial dosing regimen at that time involved administering 600 million IU interferon three times per week for 6 


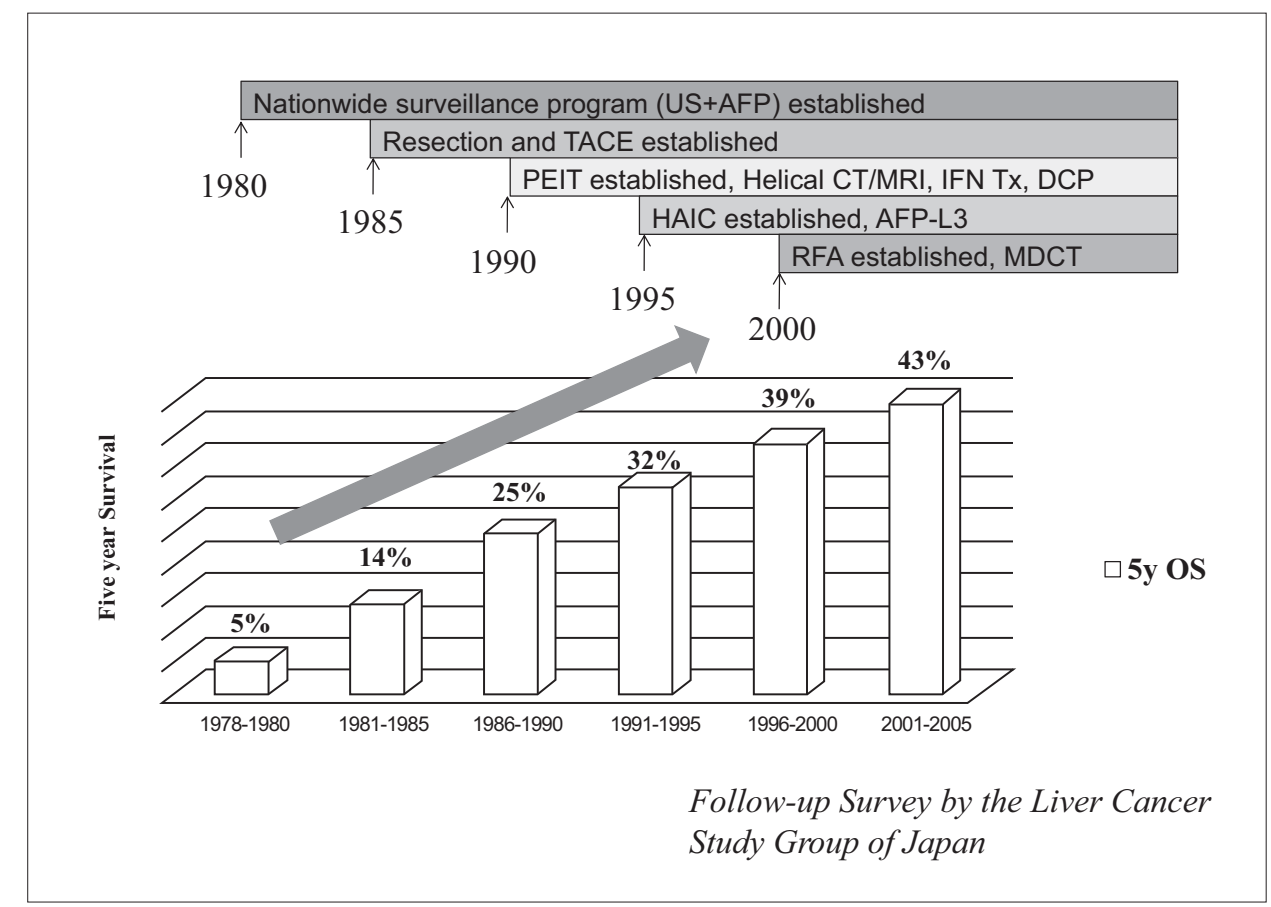

Fig. 4. Changes in liver cancer treatment outcomes: 5-year survival rate. Reproduced with permission from Kudo M [5].

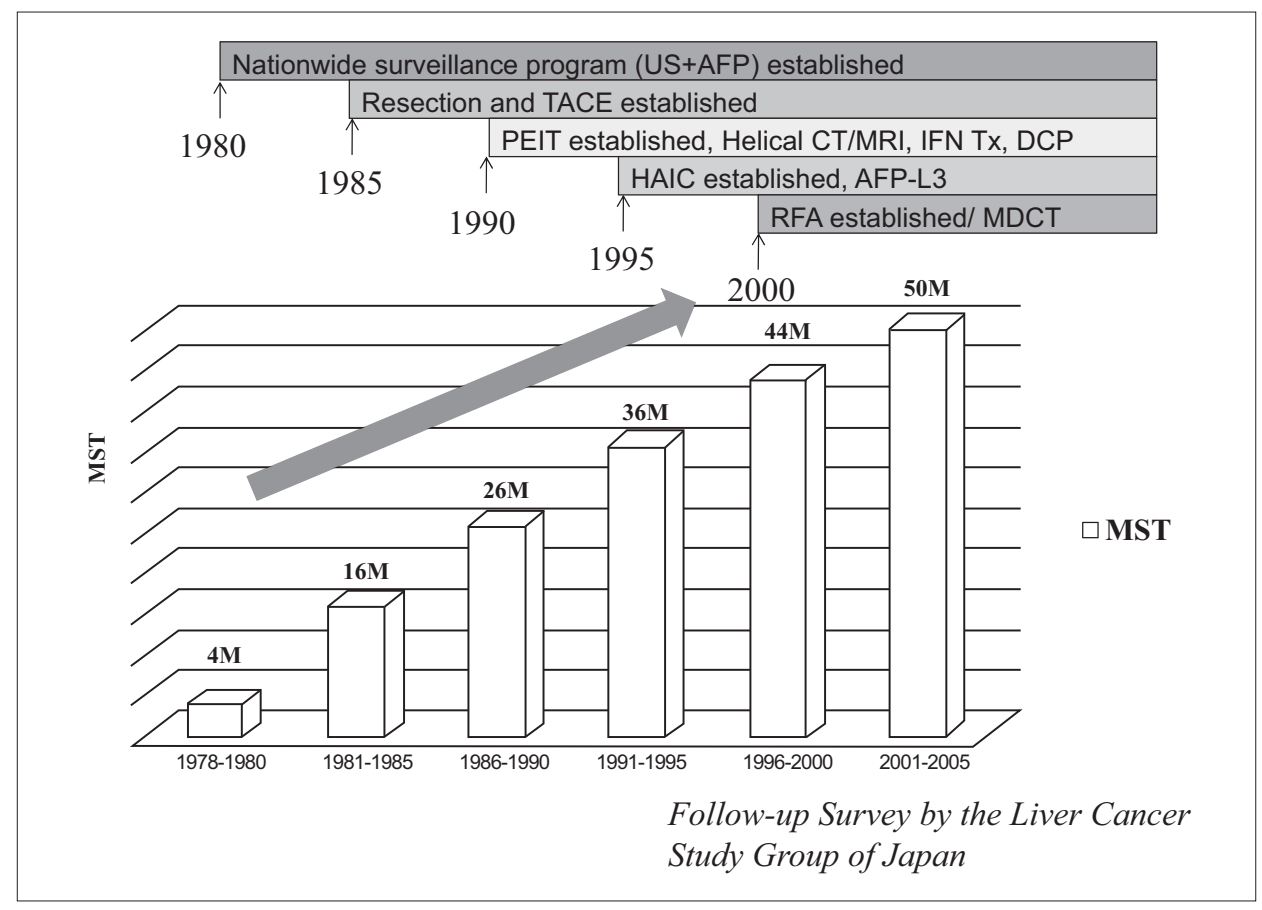

Fig. 5. Changes in liver cancer treatment outcomes: Median survival time. Reproduced with permission from Kudo M [5]. 
months, but this was gradually replaced by combination therapy with pegylated interferon (Peg-IFN) and ribavirin and triple-drug therapy with Peg-IFN, ribavirin, and a protease inhibitor. It is now possible to cure $90 \%$ of cases of genotype $1 \mathrm{~b}$ hepatitis $\mathrm{C}$ with high viral load (i.e., refractory cases) through an all oral interferon-free regimen with direct-acting antivirals. This is an important factor that has contributed to the decreased incidence and mortality of liver cancer. Because of these dramatic advancements in treating hepatitis $\mathrm{C}$, the incidence of liver cancer associated with hepatitis $\mathrm{C}$ gradually declined.

Moreover, tumor markers such as PIVKA-II (des-gamma carboxyprothrombin) and AFPL3 fraction [8] were approved and tests for them came to be routinely available in 1988 and 1996, respectively; these tests are completely covered by national health insurance in Japan. There is no doubt that the widespread use of such tumor markers has also contributed to the screening and diagnosis of liver cancer as well as to the assessment of therapeutic effects. In 1999, radiofrequency ablation (RFA) was first used in Japan; the technique was adopted very rapidly, with almost all institutions in Japan performing this procedure by 2000 . There were also dramatic advances in liver cancer diagnostics: multidetector computed tomography was introduced around 2000, Sonazoid contrast-enhanced ultrasound (CEUS) was approved in 2007, and gadolinium-ethoxybenzyl-diethylenetriamine pentaacetic acid-enhanced MRI (EOB-MRI) was approved in 2008.

CT during hepatic arteriography (CTHA) and CT during arterial portography (CTAP), which were developed by Matsui et al. at Kanazawa University, are highly precise methods of diagnosing HCC with blood flow imaging $[9,10]$. These methods can be used not only to detect small nodules precisely, but also to evaluate arterial blood flow and portal venous blood flow separately. Ultrasound angiography with intra-arterial infusion of carbon dioxide also has excellent sensitivity for detecting arterial blood flow [11], but it was used less and less after the emergence of Sonazoid CEUS and is almost never used today. One disadvantage of ultrasound angiography with intra-arterial infusion of carbon dioxide, CTHA, and CTAP is that they are invasive techniques that require an angiographic procedure. However, the sensitivity of Sonazoid CEUS for detecting arterial blood flow is comparable to that of ultrasound angiography with intra-arterial infusion of carbon dioxide, and the sensitivity of EOBMRI for detecting liver cancer is almost equivalent to that of CTHA and CTAP. Sonazoid CEUS and EOB-MRI were breakthrough advances in that they enabled the non-invasive, exhaustive diagnosis of HCC. In addition, a study using single-slice dynamic CTHA demonstrated clearly by comprehensive hemodynamic analyses that the portal vein is the tumor-draining vein in HCC, a finding that came to be known as "corona enhancement" [12]. This finding provided very important information for interpreting images taken with dynamic CT, and thereby established dynamic CT as a good diagnostic modality. Of course, it remains useful today not only in diagnosis, but also in treatment, as CT angiography machines are used for monitoring treatment procedures during TACE.

The development of defect reperfusion imaging with Sonazoid CEUS was also an epochmaking event [13]. With this method, nodules that would not be detected with B-mode ultrasound and residual cancer after RFA can be diagnosed by performing a full liver scan and reinjecting Sonazoid into areas where defects appear in the Kupffer phase. This is a very simple and extremely useful technique, but no-one considered the possibilities of this innovative procedure before its invention by Kudo et al. [13].

Advances have also been made in resection techniques. The technique of intraoperative ultrasonography for systematic subsegmentectomy developed by Makuuchi et al. [14] was a pioneering technique that came to be widely used across the world. However, in Europe and the United States, surgery is contraindicated in patients with portal hypertension and instead they are quickly scheduled for liver transplantation $[15,16]$. Nonetheless, many patients lose their eligibility status for transplantation because they progress beyond the Milan 


\section{Liver

criteria while they are waiting. It is Japan's position, therefore, that hepatectomy should actively be performed because it has a 5-year survival rate of more than $50 \%$, even in patients with portal hypertension. This unique Japanese technique for systematic subsegmentectomy should be globally recognized.

TACE was also empirically developed in Japan, and unique techniques such as superselective subsegmental TACE with lipiodol have become commonplace here $[17,18]$. However, these techniques are not usually performed in other countries, even now. One well-known historical fact is that the effectiveness of TACE itself was once doubted outside Japan. Several randomized controlled trials (RCT) of TACE versus no treatment were conducted worldwide, including Europe and the United States, with the first four RCTs showing that TACE offered no survival benefit [19]. However, physicians in other countries do not reproduce the techniques of Japanese experts in liver cancer treatment, so they do not employ superselective TACE, and this was also the case in these RCTs. Thus, patients with Child-Pugh grade B or C cirrhosis were embolized in one or both hepatic lobes, which can lead to death from hepatic failure. These factors may explain why no difference was found between the treated and untreated groups. Another failure in these RCTs was that hepatic functional reserve was not really considered an important factor in patient selection. Although currently the RCT is seen as the supreme study design for providing scientific evidence, we should bear in mind that even if a study is an RCT, its conclusions may not be valid because of problems with patient selection or treatment techniques. When these issues were pointed out by Japanese TACE experts, a new RCT was conducted at the same institution where Bruix et al. obtained their negative data [20]. This study, conducted by Llovet et al. [21], showed that TACE did offer a survival benefit [21] and the following meta-analysis of six RCTs clearly showed a survived benefit of TACE [19]. For these reasons, although Japan was the first to develop TACE, a group from Barcelona is globally recognized for making TACE the standard therapy. This was a painful lesson for Japanese researchers to learn.

Similarly, it is regrettable that hepatic arterial infusion chemotherapy (HAIC), the therapeutic effect of which has been empirically validated, is not globally recognized as the standard of care at present. Japan must be sure to avoid making the same mistake made again and must promote HAIC to the world as the standard of care. To accomplish this goal, a group led by the author and funded by a research grant from the MHLW just finished enrolling patients to a comparative randomized study of sorafenib with sorafenib plus HAIC (NCT No. 00933816). The study is about to be completed, and if it produces positive results, it will verify the survival benefit of arterial infusion chemotherapy. For this reason, the results are eagerly awaited.

One treatment developed in the West is the use of the molecular targeted agent sorafenib, which was approved in Japan in 2009. It was approved in Europe and North America in succession in 2007 and 2008, and is presently the only drug in the world that offers a survival benefit [22]. Sorafenib is indicated for Child-Pugh grade A cirrhosis patients with advanced HCC involving vascular invasion or extrahepatic spread and for patients with intermediatestage HCC that does not respond to TACE [23]. However, the survival benefit is not large: it is mild to moderate. Therefore, the most effective way to use sorafenib may be to combine it with a conventional treatment such as TACE $[24,25]$ or arterial infusion chemotherapy. The results of clinical studies with such combination treatments are also eagerly awaited. 
Table 1. Global liver cancer treatment outcomes: results of the GIDEON study

\begin{tabular}{lll}
\hline & $\mathrm{n}$ & MST, months $(95 \% \mathrm{CI})$ \\
\hline Japan & 500 & $79.6(62.1-96.0)$ \\
European Union & 1115 & $25.0(22.9-28.7)$ \\
Asia Pacific & 955 & $20.9(17.3-25.2)$ \\
South America & 90 & $19.5(13.5-\mathrm{NE})$ \\
North America & 553 & $14.8(13.1-17.0)$ \\
\hline
\end{tabular}

MST = median survival time; $\mathrm{CI}=$ confidence interval; $\mathrm{NE}=$ Not, evaluable. Reproduced with permission from Kudo M, et al. [53].

\section{Establishment of the Concept of Early HCC}

By the mid-1980s, a large number of small nodules were being detected by ultrasound in cirrhotic livers, and many of these did not exhibit the classical HCC feature of arterial enhancement with late washout on corona enhancement on CT/MRI or CT angiography [12]. Starting around this time, institutions across Japan began to actively perform liver tumor biopsies. However, it was initially very difficult to diagnose liver cancer because it was not possible to identify the characteristic features of classical liver cancer on histological findings from liver tumor biopsy, and only hyperplasia could be observed. During this period, the Japan Liver Tumor Biopsy Study Group was established and sparked lively discussion between clinicians and pathologists. These discussions also inspired the establishment of MHLW research groups on the diagnosis of early HCC that were primarily led by Masamichi Kojiro of Kurume University and Setsuo Hirohashi of the National Cancer Center. Research conducted by such study groups and MHLW-funded groups on methods such as follow-up biopsies revealed that hypovascular nodules that do not demonstrate hypervascularity are either precancerous lesions or tumors in the early stage of carcinogenesis. The third edition of the General Rules for the Clinical and Pathological Study of Primary Liver Cancer published by the Liver Cancer Study Group of Japan, published as far back as February 1992, describes "early-stage, well-differentiated HCC where the existing liver structure is not highly damaged" [26, 27], which seems very cutting-edge in retrospect.

As a result of this observational research, it was verified that HCC shows multistep carcinogenesis in which a sequence from dysplastic nodule (DN) to an early HCC within a DN (nodule in nodule), an early HCC, and finally to classical hypervascular HCC. This is another highly significant finding. Until just recently, such a clinical and pathological concept of early HCC was not recognized globally because Japan was much further ahead in this field. However, the first International Consensus Group Meeting on the diagnosis of early HCC was organized by Masamichi Kojiro at Kurume University in 2002; a second meeting was later held at Leuven (hosted by Tania Roskams), Belgium, in 2004; and a third and final consensus meeting was held in Thessaloniki, Greece, in 2006. Through these meetings, a consensus emerged from leading liver pathologists in Asia (mainly from Korea and Japan), Europe, Australia, South America, and the United States, and a consensus paper on early HCC was published in Hepatology in 2009 [28]. This paper brought about global recognition of the concept of early HCC. The article was even referenced in a WHO "Blue Book" [29], and its contents are now globally established as common knowledge. 
At around the same time, following the emergence of EOB-MRI in 2008, it was found that hypovascular nodules that do not exhibit reduced portal flow exhibit low signal intensity in the hepatocyte phase of EOB-MRI, and that such nodules are early HCC with decreased expression of OATP8 (1B3) [30-32]. It is now known that when such nodules follow their natural course, many eventually become hypervascular and progress to classical hypervascular HCC [33-51]. For these reasons, it has recently become a reality in the diagnosis of early HCC that among existing imaging diagnostic modalities, EOB-MRI is achieving a level of diagnostic performance approaching that of liver pathology experts. Such facts will soon be shared with Europe and the United States through the publication of many Japanese studies.

\section{Improvements in the Prognosis of Liver Cancer}

Japan's comprehensive screening system, advances in diagnostic approach, and careful application of recently developed treatment methods have improved the 5-year survival rate from $5 \%$ in 1978 to $43 \%$ in a nationwide follow-up survey conducted by the Liver Cancer Study Group of Japan between 1978 and 2005 (fig. 4)[5]. In addition, MST has improved from 4 months to 50 months over the past 28 years (fig. 5)[5]. This is an exceptional treatment outcome that no other country in the world has come close to achieving; for example, the 5-year survival rate for liver cancer is $11 \%$ in the United States [52], 19\% in South Korea, and 20\% in Taiwan. Clearly, the survival rate for liver cancer in Japan is by far the best in the world.

One more set of data that illustrates the superiority of Japan's treatment outcomes for liver cancer is the non-interventional GIDEON study, in which MST was 79.6 months in Japan compared to 25 months in European Union member countries, 20.9 months in the Asia Pacific region, 14.8 months in the United States, and 19.5 months in Latin America [53].The prognosis for patients with liver cancer is considerably better in Japan (table 1).

\section{Advancements in Basic Research}

The prognosis of liver cancer has conventionally been determined based on TNM staging and hepatic functional reserve. However, physicians are now beginning to understand that the prognosis of liver tumors of the same size that are treated by curative therapy can differ immensely. This is because some liver cancers have stem cell features that are thought to indicate the presence of EpCAM and AFP or CK19, and it is known that the prognosis of patients who are positive for these markers is very poor. Also, in recent years, there have been many attempts to classify HCC based on molecular biology, among which a typical example is the molecular classification by Hoshida et al. [54]. According to this classification, aggressive (S1, S2) and less aggressive (S3) types of liver cancer exist, with S1 and S2 typically being HCCs with stem cell features and thus a poor prognosis [55]. Furthermore, it is becoming clear that Wnt/ $\beta$-catenin signaling induces expression of the EOB uptake transporter OATP8 $[56,57]$, and studies have shown that OATP8-positive liver cancers have a better clinical course than other liver cancers $[58,59]$. Such findings have now ushered in an age in which basic molecular classifications and molecular pathology are directly linked with the imaging findings or patient prognosis; therefore, it may also be necessary for treatment strategy to change to accommodate this subtype of HCC. That is to say, it is becoming recognized that liver cancer should be actively subclassified to determine the prognosis and to consider the treatment strategy. These molecular classification systems are also gaining attention for their use in identifying new target molecules. 


\section{Conclusion}

Japan is the only developed country that has faced a high incidence of both hepatitis B-related liver cancer in the past and hepatitis C-related liver cancer in the past 30 years. Hepatitis B-related liver cancer has been conquered, and hepatitis-C related liver cancer is now facing the same fate. The favorable treatment outcomes we have obtained in Japan were made possible by our unique approach to screening via a nationwide surveillance program, a precise diagnostic algorithm, and a careful treatment strategy, and these factors have given us the best treatment outcomes in the world. Despite liver cancer incidence and mortality decreasing in Japan, it is likely that liver cancer will remain a major cause of death at least over the next 20 years. Furthermore, although NASH and metabolic syndrome do not have the same level of impact as hepatitis B or C, the number of cases of non-B and non-C liver cancer associated with these two diseases is undoubtedly increasing.

Japan will have an important role to play in tackling the future challenges of (1) how to establish a surveillance system for non-B and non-C liver cancer to promote early detection, (2) how to identify factors that predict carcinogenesis in patients with hepatitis C after SVR and how to establish a follow-up system, and (3) how to expand the surveillance, diagnosis, and treatment systems successfully established in Japan to the rest of the world, including Western countries.

\section{References}

1 http://globocan.iarc.fr/Default.aspx.

$\checkmark 2$ Kudo M: Japan's successful model of nationwide hepatocellular carcinoma surveillance highlighting the urgent need for global surveillance. Liver Cancer 2012;1:141-143.

-3 Mise Y, Sakamoto Y, Ishizawa T, Kaneko J, Aoki T, Hasegawa K, Sugawara Y, Kokudo N: A worldwide survey of the current daily practice in liver surgery. Liver Cancer 2013;2:55-66.

4 Lin SM: Local ablation for hepatocellular carcinoma in Taiwan. Liver Cancer 2013;2:73-83.

5 Kudo M: Surveillance, treatment and outcome of HCC in Japan”, ILCA Symposium 3 "Noevel opportunities for treatment in HCC". ILCA 2014, Kyoto. (http://www.ilca2014.org/programme.aspx).

6 Yamada R, Sato M, Kawabata M, Nakatsuka H, Nakamura K, Takashima S: Hepatic artery embolization in 120 patients with unresectable hepatoma. Radiology 1983;148:397-401.

7 Ueshima K, Kudo M, Takita M, Nagai T, Tatsumi C, Ueda T, Kitai S, Ishikawa E, Yada N, Inoue T, Hagiwara S, Minami Y, Chung H, Sakurai T: Des- $\gamma$-carboxyprothrombin may be a promising biomarker to determine the therapeutic efficacy of sorafenib for hepatocellular carcinoma. Dig Dis 2011;29:321-325.

-8 Kudo M: Alpha-fetoprotein-L3: useful or useless for hepatocellular carcinoma? Liver Cancer 2013;2:151152.

-9 Matsui O, Kadoya M, Kameyama T, Yoshikawa J, Takashima T, Nakanuma Y, Unoura M, Kobayashi K, Izumi $\mathrm{R}$, Ida M, et al: Benign and malignant nodules in cirrhotic livers: distinction based on blood supply. Radiology 1991;178:493-497.

10 Hayashi M, Matsui O, Ueda K, Kawamori Y, Kadoya M, Yoshikawa J, Gabata T, Takashima T, Nonomura A, Nakanuma Y: Correlation between the blood supply and grade of malignancy of hepatocellular nodules associated with liver cirrhosis: evaluation by CT during intraarterial injection of contrast medium. AJR Am J Roentgenol 1999;172:969-976.

11 Kudo M, Tomita S, Tochio H, Mimura J, Okabe Y, Kashida H, Hirasa M, Ibuki Y, Todo A: Small hepatocellular carcinoma: diagnosis with US angiography with intraarterial CO2 microbubbles. Radiology 1992;182:155-160.

$\$ 12$ Ueda K, Matsui O, Kawamori Y, Nakanuma Y, Kadoya M, Yoshikawa J, Gabata T, Nonomura A, Takashima T: Hypervascular hepatocellular carcinoma: evaluation of hemodynamics with dynamic CT during hepatic arteriography. Radiology 1998;206:161-166.

13 Kudo M, Hatanaka K, Maekawa K: Newly developed novel ultrasound technique, defect reperfusion ultrasound imaging, using Sonazoid in the management of hepatocellular carcinoma. Oncology 2010;78(Suppl 1):40-45.

14 Makuuchi M, Hasegawa H, Yamazaki S: Ultrasonically guided subsegmentectomy. Surg Gynecol Obstet 1985;161:346-350.

15 Bruix J, Sherman M American Association for the Study of Liver Diseases: Management of hepatocellular carcinoma: an update. Hepatology 2011;53:1020-1022. 
16 Llovet JM, Ducreux M, et al European Association For The Study Of The Liver European Organisation For Research And Treatment Of Cancer: EASL-EORTC clinical practice guidelines: management of hepatocellular carcinoma. J Hepatol 2012;56:908-943.

17 Takayasu K, Arii S, Ikai I, Omata M, Okita K, Ichida T, Matsuyama Y, Nakanuma Y, Kojiro M, Makuuchi M, Yamaoka Y, Liver Cancer Study Group of Japan: Prospective cohort study of transarterial chemoembolization for unresectable hepatocellular carcinoma in 8510 patients. Gastroenterology 2006;131:461-469.

18 Miyayama S, Matsui O, Yamashiro M, Ryu Y, Kaito K, Ozaki K, Takeda T, Yoneda N, Notsumata K, Toya D, Tanaka N, Mitsui T: Ultraselective transcatheter arterial chemoembolization with a 2-f tip microcatheter for small hepatocellular carcinomas: relationship between local tumor recurrence and visualization of the portal vein with iodized oil. J Vasc Interv Radiol 2007;18:365-376.

19 Llovet JM, Burroughs A, Bruix J: Hepatocellular carcinoma. Lancet 2003;362:1907-1917.

-20 Bruix J, Llovet JM, Castells A, Montañá X, Brú C, Ayuso MC, Vilana R, Rodés J: Transarterial embolization versus symptomatic treatment in patients with advanced hepatocellular carcinoma: results of a randomized, controlled trial in a single institution. Hepatology 1998;27:1578-1583.

-21 Llovet JM, Real MI, Montaña X, Planas R, Coll S, Aponte J, Ayuso C, Sala M, Muchart J, Solà R, Rodés J, Bruix J, Barcelona Liver Cancer Group: Arterial embolisation or chemoembolisation versus symptomatic treatment in patients with unresectable hepatocellular carcinoma: a randomised controlled trial. Lancet 2002;359:1734-1739.

22 Llovet JM, Ricci S, Mazzaferro V, Hilgard P, Gane E, Blanc JF, de Oliveira AC, Santoro A, Raoul JL, Forner A, Schwartz M, Porta C, Zeuzem S, Bolondi L, Greten TF, Galle PR, Seitz JF, Borbath I, Häussinger D, Giannaris T, Shan M, Moscovici M, Voliotis D, Bruix J, SHARP Investigators Study Group: Sorafenib in advanced hepatocellular carcinoma. N Engl J Med 2008;359:378-390.

23 Kudo M, Matsui O, Izumi N, et al: JSH consensus-based clinical practice guideline for the management of hepatocellular carcinoma: 2014 update by the Liver Cancer Study Group of Japan. Liver Cancer 2014;3:458468.

24 Kim HY, Park JW: Clinical trials of combined molecular targeted therapy and locoregional therapy in hepatocellular carcinoma: past, present, and future. Liver Cancer 2014;3:9-17.

25 Raoul JL, Gilabert M, Piana G: How to define transarterial chemoembolization failure or refractoriness: a European perspective. Liver Cancer 2014;3:119-124.

26 Kudo M: Early hepatocellular carcinoma: definition and diagnosis. Liver Cancer 2013;2:69-72.

-27 Liver Cancer Study Group of Japan: General rules for the clinical and pathological study of primary liver cancer. 3rd English edition, Kanehara \& Co., Ltd. Tokyo; 2010.

-28 International Consensus Group for Hepatocellular NeoplasiaThe International Consensus Group for Hepatocellular Neoplasia: Pathologic diagnosis of early hepatocellular carcinoma: a report of the international consensus group for hepatocellular neoplasia. Hepatology 2009;49:658-664.

29 Theise ND, Park YN, Curado M: P., et al. Hepatocellular carcinoma; in Bosman FT, Carneiro F, Hruban RH, Theise ND (eds): WHO classification of tumours of the digestive system, ed 4. Lyon, IARC, 2010;205-216.

30 Ichikawa T, Sano K, Morisaka H: Diagnosis of pathologically early HCC with EOB-MRI: experiences and current consensus. Liver Cancer 2014;3:97-107.

-31 Narita M, Hatano E, Arizono S, Miyagawa-Hayashino A, Isoda H, Kitamura K, Taura K, Yasuchika K, Nitta T, Ikai I, Uemoto S: Expression of OATP1B3 determines uptake of Gd-EOB-DTPA in hepatocellular carcinoma. J Gastroenterol 2009;44:793-798.

32 Kitao A, Matsui O, Yoneda N, Kozaka K, Shinmura R, Koda W, Kobayashi S, Gabata T, Zen Y, Yamashita T, Kaneko S, Nakanuma Y: The uptake transporter OATP8 expression decreases during multistep hepatocarcinogenesis: correlation with gadoxetic acid enhanced MR imaging. Eur Radiol 2011;21:2056-2066.

-33 Matsuda M, Tsuda T, Yoshioka S, Murata S, Tanaka H, Hirooka M, Hiasa Y, Mochizuki T: Incidence for progression of hypervascular HCC in hypovascular hepatic nodules showing hyperintensity on gadoxetic acidenhanced hepatobiliary phase in patients with chronic liver diseases. Jpn J Radiol 2014;32:405-413.

34 Jang KM, Kim SH, Kim YK, Choi D: Imaging features of subcentimeter hypointense nodules on gadoxetic acid-enhanced hepatobiliary phase MR imaging that progress to hypervascular hepatocellular carcinoma in patients with chronic liver disease. Acta Radiol 2014 (Epub ahead of print).

-35 Komatsu N, Motosugi U, Maekawa S, Shindo K, Sakamoto M, Sato M, Tatsumi A, Miura M, Amemiya F, Nakayama Y, Inoue T, Fukasawa M, Uetake T, Ohtaka M, Sato T, Asahina Y, Kurosaki M, Izumi N, Ichikawa T, Araki T, Enomoto N: Hepatocellular carcinoma risk assessment using gadoxetic acid-enhanced hepatocyte phase magnetic resonance imaging. Hepatol Res 2014:44:1339-1346.

-36 Iannicelli E, Di Pietropaolo M, Marignani M, Briani C, Federici GF, Delle Fave G, David V: Gadoxetic acidenhanced MRI for hepatocellular carcinoma and hypointense nodule observed in the hepatobiliary phase. Radiol Med (Torino) 2014;119:367-376.

-37 Inoue T, Hyodo T, Murakami T, Takayama Y, Nishie A, Higaki A, Korenaga K, Sakamoto A, Osaki Y, Aikata H, Chayama K, Suda T, Takano T, Miyoshi K, Koda M, Numata K, Tanaka H, Iijima H, Ochi H, Hirooka M, Imai Y, Kudo M: Hypovascular hepatic nodules showing hypointense on the hepatobiliary-phase image of Gd-EOBDTPA-enhanced MRI to develop a hypervascular hepatocellular carcinoma: a nationwide retrospective study on their natural course and risk factors. Dig Dis 2013;31:472-479.

38 Ichikawa S, Ichikawa T, Motosugi U, Sano K, Morisaka H, Enomoto N, Matsuda M, Fujii H, Araki T: Presence of a hypovascular hepatic nodule showing hypointensity on hepatocyte-phase image is a risk factor for hypervascular hepatocellular carcinoma. J Magn Reson Imaging 2014;39:293-297. 
39 Toyoda H, Kumada T, Tada T, Niinomi T, Ito T, Sone Y, Kaneoka Y, Maeda A: Non-hypervascular hypointense nodules detected by Gd-EOB-DTPA-enhanced MRI are a risk factor for recurrence of HCC after hepatectomy. J Hepatol 2013;58:1174-1180.

40 Hyodo T, Murakami T, Imai Y, Okada M, Hori M, Kagawa Y, Kogita S, Kumano S, Kudo M, Mochizuki T: Hypovascular nodules in patients with chronic liver disease: risk factors for development of hypervascular hepatocellular carcinoma. Radiology 2013;266:480-490.

-41 Kim YK, Lee WJ, Park MJ, Kim SH, Rhim H, Choi D: Hypovascular hypointense nodules on hepatobiliary phase gadoxetic acid-enhanced MR images in patients with cirrhosis: potential of DW imaging in predicting progression to hypervascular HCC. Radiology 2012;265:104-114.

-42 Kobayashi S, Matsui O, Gabata T, Koda W, Minami T, Ryu Y, Kozaka K, Kitao A: Intranodular signal intensity analysis of hypovascular high-risk borderline lesions of HCC that illustrate multi-step hepatocarcinogenesis within the nodule on Gd-EOB-DTPA-enhanced MRI. Eur J Radiol 2012;81:3839-3845.

43 Kobayashi S, Matsui O, Gabata T, Koda W, Minami T, Ryu Y, Kozaka K, Kitao A: Relationship between signal intensity on hepatobiliary phase of gadolinium ethoxybenzyl diethylenetriaminepentaacetic acid (GdEOB-DTPA)-enhanced MR imaging and prognosis of borderline lesions of hepatocellular carcinoma. Eur J Radiol 2012;81:3002-3009.

44 Kobayashi S, Matsui O, Gabata T, Koda W, Minami T, Ryu Y, Kawai K, Kozaka K: Gadolinium ethoxybenzyl diethylenetriamine pentaacetic acid-enhanced magnetic resonance imaging findings of borderline lesions at high risk for progression to hypervascular classic hepatocellular carcinoma. J Comput Assist Tomogr 2011;35:181-186.

45 Joishi D, Ueno A, Tanimoto A, Okuda S, Masugi Y, Emoto K, Okuma K, Sakamoto M, Imai Y, Kuribayashi S: Natural course of hypovascular nodules detected on gadoxetic acid-enhanced MR imaging: presence of fat is a risk factor for hypervascularization. Magn Reson Med Sci 2013;12:281-287.

-46 Motosugi U: Hypovascular hypointense nodules on hepatocyte phase gadoxetic acid-enhanced MR images: too early or too progressed to determine hypervascularity. Radiology 2013;267:317-318.

-47 Takechi M, Tsuda T, Yoshioka S, Murata S, Tanaka H, Hirooka M, Mochizuki T: Risk of hypervascularization in small hypovascular hepatic nodules showing hypointense in the hepatobiliary phase of gadoxetic acidenhanced MRI in patients with chronic liver disease. Jpn J Radiol 2012;30:743-751.

-48 Takayama Y, Nishie A, Nakayama T, Asayama Y, Ishigami K, Kakihara D, Ushijima Y, Fujita N, Hirakawa M, Honda H: Hypovascular hepatic nodule showing hypointensity in the hepatobiliary phase of gadoxetic acid-enhanced MRI in patients with chronic liver disease: prediction of malignant transformation. Eur J Radiol 2012;81:3072-3078.

-49 Akai H, Matsuda I, Kiryu S, Tajima T, Takao H, Watanabe Y, Imamura H, Kokudo N, Akahane M, Ohtomo K: Fate of hypointense lesions on Gd-EOB-DTPA-enhanced magnetic resonance imaging. Eur J Radiol 2012;81:2973-2977.

50 Motosugi U, Ichikawa T, Sano K, Sou H, Onohara K, Muhi A, Amemiya F, Enomoto N, Matsuda M, Fujii H, Araki T: Outcome of hypovascular hepatic nodules revealing no gadoxetic acid uptake in patients with chronic liver disease. J Magn Reson Imaging 2011;34:88-94.

- 51 Kumada T, Toyoda H, Tada T, Sone Y, Fujimori M, Ogawa S, Ishikawa T: Evolution of hy pointense hepatocellular nodules observed only in the hepatobiliary phase of gadoxetate disodium-enhanced MRI. AJR Am J Roentgenol 2011;197:58-63.

52 El-Serag HB: Hepatocellular carcinoma. N Engl J Med 2011;365:1118-1127.

53 Kudo M, Lencioni R, Ye SL, et al: ILCA 2013, Washington D.C. http://webcasts.nextmeeting.eu/event/ ilca2013/presentation/130.

54 Hoshida Y, Toffanin S, Lachenmayer A, Villanueva A, Minguez B, Llovet JM: Molecular classification and novel targets in hepatocellular carcinoma: recent advancements. Semin Liver Dis 2010;30:35-51.

55 Kudo M: Recent advances in bioinformatics reveal the molecular heterogeneity of hepatocellular carcinoma. Liver Cancer 2014;3:68-70.

56 Yoneda N, Matsui O, Kitao A, Kozaka K, Gabata T, Sasaki M, Nakanuma Y, Murata K, Tani T: Beta-cateninactivated hepatocellular adenoma showing hyperintensity on hepatobiliary-phase gadoxetic-enhanced magnetic resonance imaging and overexpression of OATP8. Jpn J Radiol 2012;30:777-782.

57 Yamashita T, Kitao A, Matsui O, Hayashi T, Nio K, Kondo M, Ohno N, Miyati T, Okada H, Yamashita T, Mizukoshi E, Honda M, Nakanuma Y, Takamura H, Ohta T, Nakamoto Y, Yamamoto M, Takayama T, Arii S, Wang $\mathrm{X}$, Kaneko S: Gd-EOB-DTPA-enhanced magnetic resonance imaging and alpha-fetoprotein predict prognosis of early-stage hepatocellular carcinoma. Hepatology 2014;60:1674-1685.

-58 Kitao A, Matsui O, Yoneda N, Kozaka K, Kobayashi S, Koda W, Gabata T, Yamashita T, Kaneko S, Nakanuma Y, Kita R, Arii S: Hypervascular hepatocellular carcinoma: correlation between biologic features and signal intensity on gadoxetic acid-enhanced MR images. Radiology 2012;265:780-789.

59 Yoneda N, Matsui O, Kitao A, Kita R, Kozaka K, Koda W, Kobayashi S, Gabata T, Ikeda H, Nakanuma Y: Hypervascular hepatocellular carcinomas showing hyperintensity on hepatobiliary phase of gadoxetic acid-enhanced magnetic resonance imaging: a possible subtype with mature hepatocyte nature. Jpn J Radiol 2013;31:480-490. 